\title{
Overcoming Learning Difficulties with Smartphones in an Inclusive Primary Science Class
}

\author{
Kati Sormunen ${ }^{1}$, Jari Lavonen ${ }^{1,2} \&$ Kalle Juuti ${ }^{1}$ \\ ${ }^{1}$ Faculty of Educational Sciences, University of Helsinki, Helsinki, Finland \\ ${ }^{2}$ Department of Childhood Education and Centre for Education Practice Research, University of Johannesburg, \\ Soweto, South Africa \\ Correspondence: Kati Sormunen, Faculty of Educational Sciences, University of Helsinki, Siltavuorenpenger 5A, \\ PL 9, 00014 University of Helsinki, Finland. E-mail: kati.sormunen@helsinki.fi
}

Received: February 4, 2019 Accepted: March 5, 2019 Online Published: March 29, 2019

doi:10.5539/jel.v8n3p21 URL: https://doi.org/10.5539/jel.v8n3p21

\begin{abstract}
This paper examines how pupils with learning difficulties (LDs) used smartphones as supportive learning tools in an inclusive science class and how the usage developed over a two-year period. The case study was conducted in a Finnish primary school, where nine LD pupils' smartphone usage was followed in three science learning practices that supported LDs. The data consisted of repeated smartphone questionnaires, interviews, learning outcomes, and teachers' memoranda. The content and co-occurrence network analysis revealed that the smartphone usage varied in different practices, and its benefits developed gradually during the research period. Research highlights that teachers' and pupils' engagement with a dedicated, collaborative, and long-lasting process of smartphone usage in teaching and learning enables the achievement of change.
\end{abstract}

Keywords: case study, digital technology, inclusion, learning difficulties, science, smartphones

\section{Introduction}

Following the principle of inclusion, there are more and more pupils with a wide variety of learning difficulties (LDs) in mainstream classrooms (e.g., Graham \& Jahnukainen, 2011). In Finland, the Basic Education Act $(642 / 2010)$ requires schools to organize educational support for pupils' growth, learning, and school attendance, including pupils with mild and severe LDs as well. Recent studies have indicated that many teachers face problems when implementing inclusive education in classrooms, both in Finland (Paju, Räty, Pirttimaa, \& Kontu, 2015; Pesonen et al., 2014) and in other countries (Bešić, Paleczek, Krammer, \& Gasteiger-Klicpera, 2017). However, carefully implemented inclusive pedagogy can create an optimal and rich learning environment for every pupil, including those with LDs (Bešić et al., 2017; Florian, 2010).

For teachers, what qualifies as good inclusive pedagogy is not always straightforward overall or in specific subjects. Florian's (2014) inclusive pedagogical approach in action (IPAA) framework was designed as a tool to capture evidence of inclusion in classroom settings. The framework relies on three main assumptions of inclusive pedagogy. In the first assumption, differences are accounted for as an essential aspect of human development in any conceptualization of learning; the pupils' differences are accepted, and every pupil's potential and ability to progress is recognized. The second assumption focuses both on teachers' professional beliefs that they are capable and qualified for teaching all pupils and on pupils' difficulties, which are considered as dilemmas for teaching. In the third assumption, teachers are committed to continuing their professional development, continually developing creative new ways of working with other adults and professionals, and modelling and testing new ways to develop inclusive practices (Florian, 2014). In this paper, relying on the IPAA framework, especially on the third assumption, we report a two-year case study within inclusive science lessons, where digital technology was modelled and tested in a novel way to support effective science learning practices. In science classes, the beneficial impact of using digital technology alongside effective learning and teaching practices has been widely researched (Sakarneh \& Nair, 2014); however, this beneficial impact has rarely been studied over an extended period in an inclusive class that takes into account the diversity and complexity of LD pupils. Our aim is to fill this research gap by focusing on developing smartphone usage that relies on research-based, effective science practices and not only technology-driven usage (Brodin \& Lindstrand, 2003). 


\subsection{Supporting LD Pupils'Science Learning with Digital Technology}

In Finnish education practices, LDs are often described as problems in language (reading, writing, speaking, listening), mathematics, attention and action control, perception, and fine or gross motor skills. It is generally understood that these difficulties might negatively affect pupils' self-esteem and their overall sense of wellbeing (Niilo Mäki Instituutti, 2015). In science classes, these difficulties may influence academic skills, functional skills (such as skills needed for inquiry processes), and social skills (especially with respect to scientific communication; Bell, 2002; Lee \& Buxton, 2011; Lee \& Fradd, 1996). These difficulties not only weaken pupils' achievements, but they may also weaken their self-esteem and interest in learning.

In primary science, pupils are required to learn and understand specific concepts and vocabulary. These concepts are essential for explaining phenomena scientifically, evaluating and designing scientific inquiry, and interpreting data and evidence $(\mathrm{OECD}, 2016)$. Previous research has indicated that language-related difficulties particularly affect scientific knowledge building when pupils have difficulties identifying the right concept, learning specialized vocabulary, or using it in the right context (Wellington \& Wellington, 2002). If the language used in the class is unfamiliar to the pupil, there will be difficulties in language processing, following instructions, and retaining and applying previously-learned knowledge (Bell, 1998). Therefore, hands-on methods and activity- and inquiry-oriented approaches have been found to be beneficial for LD pupils (Bell, 2002; Lee \& Buxton, 2011; Lee \& Fradd, 1996; Lee \& So, 2014; McGinnis \& Kahn, 2014). Working in a natural context, where concept acquisition and explanation are conducted in a familiar and simple language, promotes learning (Lee \& Buxton, 2011; Wellington \& Wellington, 2002). However, inquiry-oriented science learning featuring unstructured, poorly planned, open-ended investigations or prediction-making without context may be difficult for LD pupils (Bell, 1998; Brigham, Scruggs \& Mastropieri, 2011; Wellington \& Wellington, 2002). Language-related difficulties also affect collaborative learning situations, where scientific communication, reasoning, idea expression, and general social interaction with peers can be challenging (Bell, 1998; Wellington $\&$ Wellington, 2002). However, teachers can effectively inspire collaboration in a group setting by assigning complementary and interconnected roles according to each pupil's strengths (Johnson \& Johnson, 2013).

There is research-based evidence that digital technology can offer support for learning (Sakarneh \& Nair, 2014), but pedagogical modifications are often needed in inclusive classes since each LD appears differently and often in different combinations. Without carefully planned instruction, information and interaction overload might become chaotic for LD pupils (Motiwalla, 2007). The research field lacks comprehensive studies of the benefits of smartphones for LD pupils' science learning. Nonetheless, existing studies provide valuable information on successful digital technology integration in the classroom when LD pupils' learning needs are taken into consideration (Drigas \& Ioannidou, 2013). In what follows, the possible support of digital technology is discussed further through the lens of previous research considering LD-supportive science learning practices: (1) scientific knowledge building and vocabulary building; (2) activity- and inquiry-oriented learning; and (3) communication.

\subsubsection{Scientific Knowledge and Vocabulary Building}

Language-related knowledge and vocabulary building can be supported by digital technology in various ways. Writing with a technological tool can circumvent both language-related difficulties as well as difficulties in fine motor skills (Freeman, MacKinnon, \& Miller, 2004; MacArthur, 2009). Digital technology also makes alternative ways to learn, retain, and apply learning easily available. For example, pupils' thinking can be fostered through drawings, animations, information searching, and video observations (Looi et al., 2011; Fasting \& Halaas Lyster, 2005; Geer \& Sweeney, 2012). These multimodal approaches can be used in instructions, learning materials, note-making, and processing what has been learned, all of which can be beneficial to LD pupils (Brigham et al., 2011; McGinnis \& Kahn, 2014; Tomlinson, 2000). In addition, smartphones can easily provide accessible information and learning materials and, therefore, allow pupils to learn anytime and anywhere (Bouck, 2010; Song, Wong, \& Looi, 2012).

\subsubsection{Activity- and Inquiry-Oriented Learning Practices}

In activity- and inquiry-oriented learning, digital technology can support LD pupils in areas of inquiry tasks and learning materials. Inquiry tasks can be presented using a clear structure and multi-media, such as tutorial videos or picture-supported inquiry guides. Smartphones enable pupils to reflect on their learning process (Song et al., 2012) since they have user-friendly tools to capture learning moments auditorily, textually, and visually for future reflection (Looi et al., 2011). In activity- and inquiry-oriented learning, smartphones can support LD pupils' science learning by providing simplified learning materials, research functionality, and the use of working visual demonstrations (Bell, 2002; Fasting \& Halaas Lyster, 2005; Lee \& So, 2014; O'Leary, 2011). As it takes 
time for LD pupils to become familiar with new approaches, the same activity- and inquiry-methods and digital tools need to be used repeatedly in order to assess progress (Bouck, 2010; Cook \& Schirmer, 2003).

\subsubsection{Communication in the Learning Practices}

Digital, technology-supported, multimodal ways to communicate can increase LD pupils' communication and collaboration in the learning practices (Geer \& Sweeney, 2012). For example, working in virtual environments can be beneficial to LD pupils in social situations (Bishop, 2003) when various media enable pupils to capture learning moments and form a lasting, visible impression (Geer \& Sweeney, 2012; Looi et al., 2011; Song et al., 2012). In communication, smartphones should be used with similar methods for knowledge building. For instance, if it is difficult for a pupil to convince other group members vocally, multimodal approaches could be used (e.g., suitable text, audio recordings; Brigham et al., 2011; Lee \& Fradd, 1996; McGinnis \& Kahn, 2014; Tomlinson, 2000).

\subsection{Research Goal and Research Questions}

This paper presents smartphone practices that support LDs in an inclusive primary science class. More precisely, in order to find ways to personalize learning with digital technology, we focused on nine pupils with different combinations of LDs and followed them for two academic school years. The smartphone was chosen as the digital tool because it aroused interest among pupils, and its technical characteristics enabled diverse use. The research questions included: which smartphone usages actualize LD pupils' science learning process, and are there co-occurrences between particular smartphone usages and a single type of LD? Guided by these questions, the results of this study provide an overarching benefit to all pupils, regardless of learning ability.

\section{Method}

The research followed a case study methodology (Stake, 2005) to fully explore the smartphone-supported learning practices in an inclusive science education context. In order to collect high quality data, the researchers took into consideration the factors that might prevent collection. Based on Stake (2005) and Stalker (1998), it is essential that the researcher knows the participants well. In this study, the corresponding author was working in a class as a special education teacher. This familiarity increased confidence among the pupils (Stalker, 1998), and the collected data corresponded to the actual learning situation. In addition, during the data collection and analysis, the researchers kept the quality indicators of special education technology research in mind, especially the conceptualization of the study, sample selection, description of participants, implementation of interventions, outcome measures, and data analysis (Gersten \& Edyburn, 2007).

\subsection{Study Context and Participants}

This two-year case study (2012-2014) was conducted in a primary school in Helsinki, Finland. On average, one out of every six pupils had identified as having a LD and had a guarantee of enhanced support at school. This support was determined in collaboration with a multi-professional team, selected according to Finnish education practices (The Finnish Basic Education Act, 642/2010). Teachers in the school worked in teams of classroom and special education teachers to implement inclusive education. The participating class ( $n=44$ pupils; $n=10 \mathrm{LD}$ pupils) had two primary teachers and one special education teacher. The focus group consisted of ten pupils with LDs ( $n=2$ female students; $n=8$ male students). For this study, we chose nine pupils for closer examination (see Table 1 for a detailed description). One pupil was left out of the study due to several long periods of absence.

Table 1. Case study pupils' learning difficulties

\begin{tabular}{|c|c|c|c|c|c|c|c|c|}
\hline \multirow[b]{2}{*}{$\begin{array}{l}\text { Pupil (age at the } \\
\text { beginning of the study) }\end{array}$} & \multirow[b]{2}{*}{ Sex } & \multicolumn{7}{|c|}{ Learning Difficulty } \\
\hline & & $\begin{array}{l}\text { Attention and } \\
\text { action control }\end{array}$ & $\begin{array}{l}\text { Fine motor } \\
\text { skills }\end{array}$ & Language & Mathematics & Perception & Self-esteem & $\begin{array}{l}\text { Social } \\
\text { skills }\end{array}$ \\
\hline Eetu (11) & Male & $\mathrm{x}$ & $\mathrm{x}$ & & & & & \\
\hline Aleksi (11) & Male & $\mathrm{x}$ & & $\mathrm{x}$ & & & & \\
\hline Juhani (11) & Male & $\mathrm{x}$ & $\mathrm{x}$ & $\mathrm{x}$ & & & & \\
\hline Tuomas (10) & Male & & & & & $\mathrm{x}$ (social) & $\mathrm{x}$ & $\mathrm{x}$ \\
\hline Niko (10) & Male & $\mathrm{x}$ & & $\mathrm{x}$ & & & & \\
\hline Laura (12) & Female & $\mathrm{x}$ & & & $\mathrm{x}$ & & & \\
\hline Anni (12) & Female & $\mathrm{x}$ & & $\mathrm{x}$ & & & & \\
\hline Jere (11) & Male & $\mathrm{x}$ & $\mathrm{x}$ & $\mathrm{x}$ & & $\mathrm{x}$ (social) & & $\mathrm{x}$ \\
\hline Lauri (12) & Male & & $\mathrm{x}$ & $\mathrm{x}$ & & & $\mathrm{x}$ & \\
\hline
\end{tabular}


The pedagogy used in the participating class relied on Florian's (2014) IPAA framework. The teachers were engaged to co-operate, and the school management supported their work. Teaching practices focused on what was taught and how, and the support provided was available to all pupils. These inclusive science practices were gradually introduced and practiced with all pupils before the research period, which promoted inclusion in the class. In addition, most of the pupils had been in the same group since first grade, and the special education teacher had taught them throughout this time. In this study, we focused on developing new ways of working with participating pupils and teachers (Florian, 2014).

\subsection{Smartphone Usage in the Class}

During the research period, the pupils and teachers developed inclusive science learning practices that could be supported by smartphones. Digital technology (computers, laptops, tablet devices, and mobile phones) had already been systematically used in the class since the first grade, and pupils and their families were advised about age ratings, safe online usage, and cyber bullying. At the beginning of the research period, each pupil was given a smartphone (Nokia Lumia 800, Windows operating system) with mobile broadband access for internet usage but without the capability to make phone calls. Both pupils and parents committed to following a collectively-constructed netiquette (internet etiquette).

At the beginning of the research period, the participants familiarized themselves with the smartphones (Sormunen, Lavonen, \& Juuti, 2014). The e-learning space was created within a cloud service (Microsoft cloud service) to share and store all learning materials and the pupils' learning outcomes. The main focus was placed on three science projects (Figure 1). The first project was an inquiry project about water. (states of water, surface tension, buoyancy, capillarity, dissolution, and solution). The aim was to find good practices to support individual learning processes with smartphones. In the second project, the emphasis was to collaborate and to use e-learning space in collaborative note-making and interaction. Pupils studied space (the solar system, gravity, magnetism, the earth's structure, the formation of mountains, and the moon phases) by making inquiries and optional learning outcomes in mixed groups of four. In the third project, pupils studied electricity in a collaborative maker-centered project (renewable and non-renewable energy, frictional electricity, power supplies, electrical circuits, electrical safety, and using electricity to produce heat, light, and movement) (Sormunen, Juuti \& Lavonen, in press). The pupils followed a project-based learning approach in which they used scientific and engineering practices, such as questioning, observing, measuring, designing, and analyzing, as a part of constructing an artifact in collaborative groups (Krajick \& Merritt, 2012).

The pupils participated actively in the research process and in designing their learning practices. Teachers guided the pupils to use specific materials and tools suitable for their personal needs (cf., previously described studies above). They were also taught to focus on using smartphones for learning purposes at school and to reflect on situations where smartphones were beneficial to their studies. Teachers followed the pupils' smartphone usage; each pupil who used the smartphone in a novel way was given an opportunity to present and teach his/her methodology to the whole class. Teachers also offered pupils a variety of learning materials (Table 2) that were part of the everyday teaching and learning practices. Additionally, teachers encouraged pupils to use multimodal approaches to make notes during lessons. Pupils' personal files were shared with all three teachers in the cloud.

Table 2. Offered digital learning materials and introduced digital note-making practices for pupils

\begin{tabular}{ll}
\hline Digital Learning Materials & Digital Note-making Practices \\
\hline Audio files (audio books, self-recorded audio recordings) & Notebook applications (text, photos, audio files) \\
Videos & Notebook applications (text, photos, audio files) \\
Hyperlinks (videos, webpages) & Videos (self-recorded videos) \\
Informative pictures & \\
\hline
\end{tabular}

\subsection{Data Collection}

Data were collected in three phases from multiple sources (Figure 1), using various procedures to ensure the reliability of the interpretations and to reduce misinterpretation (Stake, 1998). In addition, the methods for collecting the data on pupils' smartphone use in the science lessons were developed further during the research period. In the first and second phases, the data were collected through repeated smartphone questionnaires, using the online pupil response system Socrative (www.socrative.com). In both collections, pupils reported on their smartphone use after every school day during the three-week periods. The questionnaires contained yes-no questions, such as 'I searched for information with the smartphone', 'I made notes with the smartphone', 'I used 
the smartphone to practice', and 'I had problems with the smartphone'. The yes-no questions were followed by open answers, where pupils were asked to describe their usage more specifically.

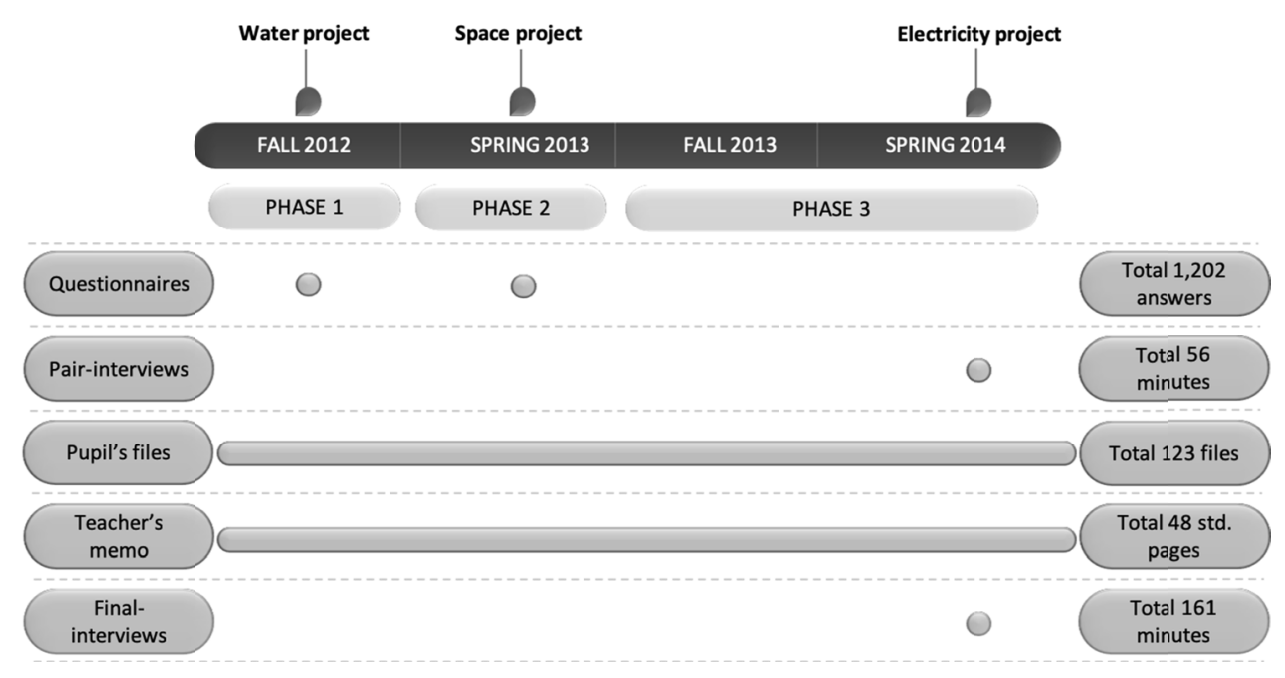

Figure 1. Research phases and the data collection

After the second phase, we found that the pupils' response rate to the questionnaires decreased. In order to make sure that we received answers from the third phase, the questionnaire was adapted into pair-interviews. The collaborative groups were interviewed in pairs after each lesson with questions similar to the questionnaires. The questionnaire provided information about smartphone usage in general and which teachers' actions enhanced the usage. In addition, pupils' files in the cloud service were saved regularly (Figure 2). When pupils were co-operating or working with the same file, the page versions and authors were detected.

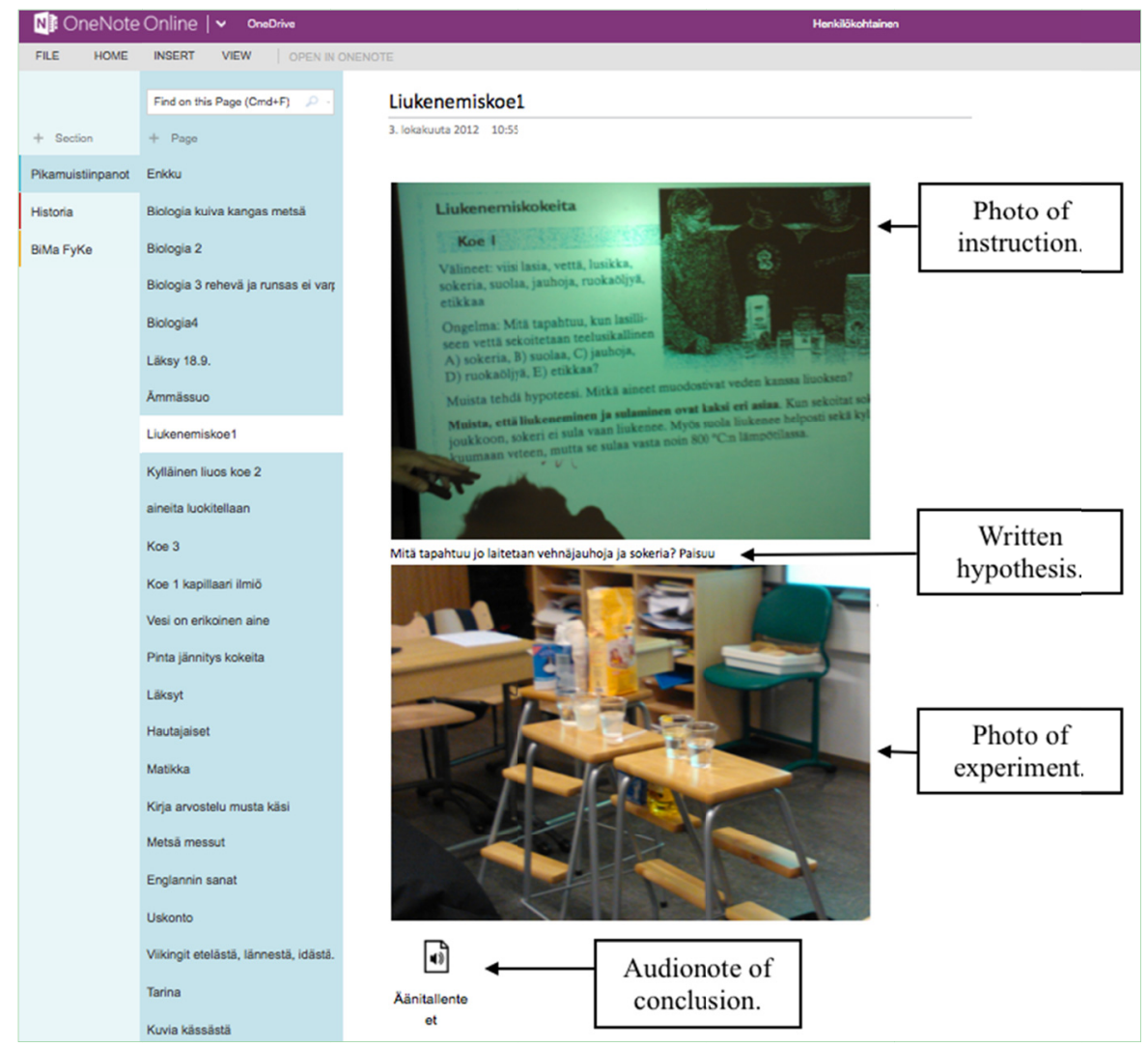

Figure 2. A LD pupil's personal note on the solution of different substances 
Throughout the two-year period, the corresponding teacher wrote memos every time the pupils operated with smartphones in science class or corresponded through email or text messages with the teachers. Pupils' smartphone usage data collected from the questionnaires and learning outcomes were compared and reflected upon in the memo. Finally, in order to ensure validity, the pupils were interviewed individually at the end of the third phase. The corresponding author conducted the final interviews on a one-on-one basis, following the stimulated recall method. We applied Tochon's (2007) notions concerning viewing past events to remember one's past thoughts using the pupils' notes, photos, and video clips as stimuli to help them recall their smartphone use.

\subsection{Data Analysis}

First, the data received from the questionnaires and pair-interviews were transcribed into the same form. Then, the pupils' files were compared with the information received from the questionnaires and pair-interviews. The files gave valuable information about the learning outcomes and the variety of media used in them. If there was divergence between the files and answers, the data were corrected. The pupils' files were also beneficial for replacing missing information. Finally, the pupils' interviews were transcribed.

In order to improve external validity and reliability, the authors of this article participated in the data analysis process (Stake, 2005). The analysis process followed an agreed upon pattern (see Cohen, Manion, \& Morrison, 2007); the corresponding author made the preliminary analysis, the results of which were discussed until a common understanding was achieved. First, the data were examined using content analysis and, then, using co-occurrence network analysis. After, the findings from the content and co-occurrence network analyses were compared with the transcribed interviews. Throughout the analysis, the text transcriptions were read several times, and the gathered data were compared.

\subsubsection{Content Analysis}

The data were systematically investigated to define the context and to receive an overall vision of the content. Then, the data were analyzed through a theory-guided content analysis (Stake, 2005). The LDs and the three science learning practices formed the theoretical categories (i.e., learning difficulties, scientific knowledge and vocabulary building, activity- and inquiry-oriented learning, communicative learning practices). Smartphone usage formed the codes under those categories, and particular smartphone usages and the LDs formed sub-codes (see Table 3). If new codes outside of the theoretical background emerged, they were discussed with all authors (denoted with asterisks in Table 3; Cohen, Manion, \& Morrison, 2007). Disturbing or any other negative codes under scientific learning practices did not emerge in the data.

Table 3. Categories of smartphone usage in the science lessons

\begin{tabular}{|c|c|c|}
\hline Theoretical category & Codes & Sub-codes \\
\hline Learning difficulties & & $\begin{array}{l}\text { Attention and action control, fine motor skills, language, } \\
\text { perception, self-esteem, social skills }\end{array}$ \\
\hline \multirow{4}{*}{$\begin{array}{l}\text { Scientific knowledge and vocabulary } \\
\text { building }\end{array}$} & Following instructions & Text, picture, photo, video, podcast \\
\hline & Multimedia information & Auditory, visual, textual \\
\hline & Making notes & \\
\hline & Reading notes & Auditory, visual, textual \\
\hline Activity- and inquiry-oriented learning & Capturing learning process & Auditory, visual, textual \\
\hline \multirow[t]{3}{*}{ Communicative learning practices } & Collaboration & Virtual environment, * group role, * continuing at home \\
\hline & Communication tools & Visible thinking, explain concepts, messaging \\
\hline & Capturing learning moments & Auditory, visual, textual \\
\hline Other & & $\begin{array}{l}* \text { Contact with the teacher, } * \text { calendar marks, }{ }^{*} \text { searching for } \\
\text { applications, *building team spirit }\end{array}$ \\
\hline
\end{tabular}

Note. ${ }^{*}$ denotes a code that emerged during this study.

Through this analysis, the potential of smartphones to support LD pupils' science learning, based on previous studies, was found (see Section 3), but its potential for specific LDs was not clarified. For example, the small number of participating pupils and their diverse combination of LDs limited the analysis and findings (see Bell, 1998). For that reason, and to enrich the analysis, we decided to employ a co-occurrence network analysis.

\subsubsection{Co-Occurrence Network Analysis}

In this paper, a co-occurrence network analysis was used to find relationships between particular LDs and types of smartphone usage as well as possible changes in usage. Notably, a co-occurrence network analysis has not 
been used to examine the co-occurrence of particular LDs with pupils' actions in the classroom. Moeller, Ivcevic, Brackett, and White (2017) used a similar method to analyze how positive and negative emotions occur together within individuals. We conducted the co-occurrence analysis with Gephi, an open-source software for data visualization (Bastian, Heymann, \& Jacomy, 2009). The six LDs, the codes, and the sub-codes from the theory-guided content analysis (smartphone usage in science lessons) were set as nodes, and the co-occurrences among particular LDs and specific smartphone usages were entered as an edges table. For example, if a pupil who presented with fine motor skills and language LDs made calendar marks with the smartphone, we noted a co-occurrence between fine motor skills and calendar marks as well as between language and calendar marks. The complete network graph of all phases is depicted in Figure 3. In this graph, each LD and recognized smartphone use is represented by colored circles and a word tag. These circles are called nodes. Co-occurrences between LDs and specific smartphone uses were visualized with the Yifan $\mathrm{Hu}$ algorithm ( $\mathrm{Hu}, 2006)$, in which nodes with a low link are pushed to the sides of the visualization, and the nodes with a higher link attract each other. Thus, a complete graph where the nodes are grouped close to each other indicates a strong internal structure of the analysis (Khokhar, 2015). The size of the node indicates the number of co-occurrences (edges) between an LD and a smartphone use, and it depends on the value of its degree centrality (Paranyushkin, 2011). The darkness of a node's color shows the variety of contexts where the node appears, and it depends on betweenness centrality (Paranyushkin, 2011). Dark green nodes are the most influential nodes in the visualization (e.g., the Phase 1 capturing learning process node in Figure 3). The connecting lines between nodes are called edges. The thickness of the connective edge lines between the nodes indicates the edges' weight (Paranyushkin, 2011). The thicker that the lines between the nodes are, the stronger the co-occurrences between them is. The complete network of connections consisted of 41 nodes (e.g., LDs and smartphone uses) and a total of 1,847 edges (e.g., the co-occurrence between a particular LD and a specific smartphone use).

Phase 1

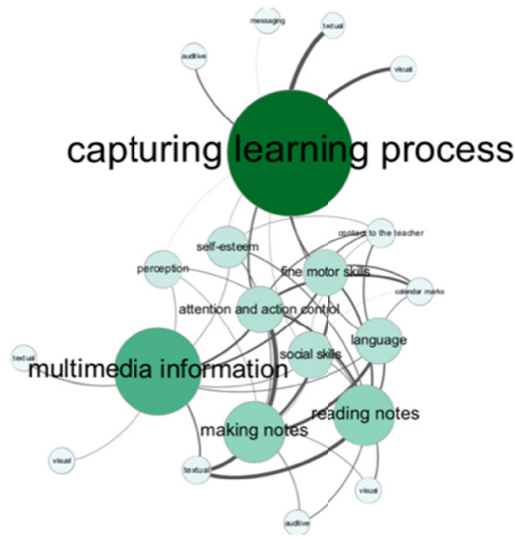

Phase 2

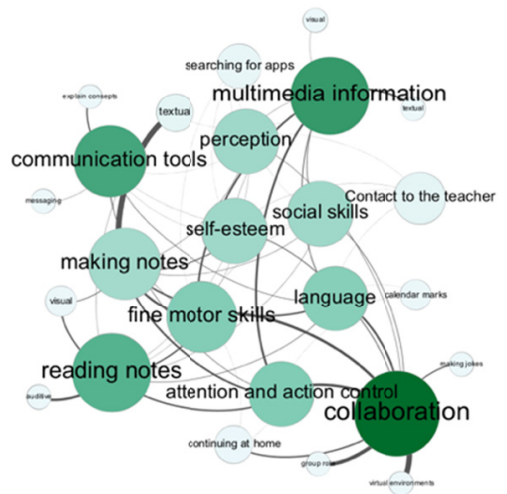

Phase 3

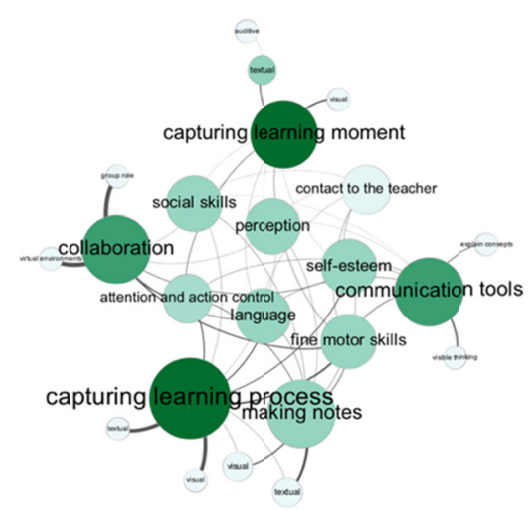

Figure 3. The complete network of co-occurrences between LDs and specific smartphone uses in all three phases

\section{Findings}

During the two-year research period, smartphone usage developed gradually in the science lessons, and beneficial smartphone usage varied in different LD-supportive science practices. These findings are represented with illustrative quotations from the pupil's final-interviews below.

\subsection{Changes in Smartphone Usage During the Research Period}

The analysis revealed that from the very beginning, pupils and teachers found the smartphones beneficial in science education (Table 4), but active usage was dependent on the contents of the projects. The disadvantages mentioned were mostly related to technical issues (e.g., battery life, bad internet connection) and not to learning practices. In the first phase, when the device was new to both the teachers and pupils, smartphones were used in all LD-supportive learning practices but mainly in knowledge and vocabulary building. Based on the questionnaire answers, all LD pupils used their smartphones actively. In the second phase, the pupils studied space in collaborative groups of four. The smartphones were mostly used in scientific knowledge and vocabulary building and in communicative learning practices. Even though the project contained inquiries (e.g., magnetism), 
the data were not found from any data source. The questionnaire answers revealed that all LD pupils continued the active use of their smartphones in the second phase.

Table 4. The frequencies of smartphone usage in the science lessons per theoretical category in the research period

\begin{tabular}{llll}
\hline Theoretical category & $\begin{array}{l}\text { Phase 1 } \\
(34.5 \% \text { of all edges })\end{array}$ & $\begin{array}{l}\text { Phase } 2 \\
(43.6 \% \text { of all edges })\end{array}$ & $\begin{array}{l}\text { Phase } 3 \\
(21.9 \% \text { of all edges })\end{array}$ \\
\hline Scientific knowledge and vocabulary building & $63.1 \%$ & $54.8 \%$ & $17.2 \%$ \\
Activity- and inquiry-oriented learning & $22.6 \%$ & $0.0 \%$ & $29.4 \%$ \\
Communicative learning process & $7.0 \%$ & $44.9 \%$ & $53.4 \%$ \\
Other & $7.2 \%$ & $0.3 \%$ & $0.0 \%$ \\
\hline
\end{tabular}

In the collaborative electricity project in the third phase, the pupils used smartphones mostly in communicative learning practices but also in activity- and inquiry-oriented learning as well as in scientific knowledge building (Table 4). In the third phase, four LD pupils (Aleksi, Jere, Laura, and Niko) did not take any notes or mention any smartphone use during the project. However, in the final-interviews, Aleksi and Niko noted the benefits of the smartphone, especially in note-making, while Jere would rather use a laptop. Only Laura preferred a paper book and notebook after the first year's experimenting: "It is much faster to write in it [paper notebook]. I'm not so quick writer with a smartphone". In the final interviews, the rest of the pupils described their overall smartphone usage a great deal, often comparing it to how things were before. Eetu described changes in his smartphone usage accordingly:

Interviewer (I): What has changed in your smartphone using?

Eetu: I make notes with it. Before you were allowed to just play.

I: What do you think about this change?

Eetu: Well, it was quite good. Like you were allowed to use phones in this school.

The visualizations of all phases (Figure 3) show how the diversity of smartphone usage developed gradually during the two-year research period. An examination of all three visualizations revealed that the nodes grouped more closely to each other as time passed. There were also more co-occurrences between the nodes, which indicates that the internal structure of the analysis was more sophisticated in the third phase (Khokhar, 2015). In other words, the visualization network was stronger, and the ways of using the smartphone had stabilized. In what follows, the detailed results are described according to the three LD-supportive science-learning practices.

\subsection{Scientific Knowledge and Vocabulary Building}

Previous research considering the possible support of smartphones in scientific knowledge and vocabulary building has emphasized multimodal instruction, learning materials, and note-making practices, especially for circumventing language-related difficulties (see Looi et al., 2009, MacArthur, 2009; Song et al., 2012). Based on the content analysis, pupils used smartphones mainly for making notes in scientific knowledge and vocabulary building practices during the research period. In fact, smartphones were only used in ways relating to note-making in the third phase. Pupils' notes were mainly textual, but some of the pupils also made auditory and visual notes (photos and small observation videos). In the first and second phases, the pupils made auditory notes, but this was not adopted as an everyday practice. In the first phase, pupils reported the use of the smartphones for note reading. The usage diminished slightly in the second phase, and, in the third phase, there was no note reading usage at all. In the second phase, pupils searched learning-supportive applications for their space project (e.g., SkyMap); although, there was little mention of using the application for star watching.

During the research period, there was no evidence of using smartphones to follow instructions even though they were offered to the pupils in the learning environment. In the first and second phases, pupils reported using their smartphones to search for information on the internet, but they did not report any use of multimodal learning materials (e.g., audio books, educational videos) even though it was offered to them (see Table 2); however, several pupils described using them in their learning.

Interviewer (I): We have had homework where you can choose to read a chapter from a book, listening to it from a podcast, or watching a video related to it. Which one you usually choose?

Eetu: Podcast. Yes, I would choose both.

I: So, book and podcast or video or podcast? 
Eetu: Video and podcast.

I: Why would you choose those?

Eetu: Well, it's easier that way.

I: Easier than reading?

Eetu: Yes.

Interviewer (I): We have had different materials in the [digital] learning space. What would you rather use when you study a new topic?

Aleksi: Well, I guess, video or podcast.

I: Why?

Aleksi: Or I read out loud. I don't know. When reading, you understand more, but nowadays, I'm quite a quick reader.

I: But before it was easier with video and podcast?

Aleksi: Yes.

The co-occurrence network analysis revealed that the co-occurrences related to knowledge and vocabulary building changed over time (Figure 3). In the first two phases, multimedia information and reading notes were two of the more important nodes, but they were not in the third phase because of alterations in the data collection. In the first and second phases, multimedia information was one of the more influential nodes (color), and it had a strong co-occurrence (thick line) with fine motor skills as well as attention and action control. The pupils with attention and action control had very strong co-occurrence with making notes in the first phase, especially with textual notes (scientific knowledge building). A strong co-occurrence between fine-motor skills and language-related difficulties was also found. The similarity to the reading notes results indicates that the pupils who had difficulties with attention and action control, fine motor skills, and language both made notes and read them in order to learn. In the second phase, a low co-occurrence with multimedia information and reading notes remained.

Based on the final-interviews, eight pupils (all students except Laura) felt that learning new topics was much easier with smartphones. Niko, who presented with difficulties in language as well as attention and action control, described his note-making in the following manner.

Interviewer (I): How do you make notes in the science lessons?

Niko: Well, if I happen to have my smartphone with me, if I don't leave it on the charger, so, then, I take it with me, and I use it. But if I forget it, then I use [paper] notebook.

I: Well, which one you prefer to use?

Niko: Well, smartphone.

I: Why do you use rather use phone or smartphone?

Niko: Well it is easier. I don't have to worry what the letters look like.

\subsection{Activity- and Inquiry-Oriented Learning}

Previous research has emphasized a technology-enhanced structure and instructions for activity- and inquiry-oriented learning practices as well as reflection on the learning process (Bouck, 2010; Fasting \& Halaas Lyster, 2005; Song et al., 2012). In this study, smartphones played a minor role in activity- and inquiry-oriented learning, and pupils reported using smartphones only for capturing the learning process. Figure 2 demonstrates how the inquiry process was captured auditorily, visually, and textually. This type of usage increased over time. The visual and textual components became the most useful ways to capture the inquiry process. In the final interviews, all pupils with fine motor skills difficulties mentioned that the smartphone was beneficial to them. The notes made in the inquiry processes were also beneficial for recalling learning situations.

Juhani: I take photos so that I can remember what we have learned. In this picture [shown in the interview; see Figure 2], we were in the lesson, and we watched how the yeast is sinking at the bottom of the water and how that sugar is mixing with the water.

The visualization in Figure 3 reveals that the dark green node for capturing the learning process was the most influential node in the first phase and was the second-most-influential node in the third phase. In the first phase, 
it had a very strong co-occurrence (thick line) with visual and textual capturing and a strong co-occurrence with attention and action control, fine motor skills, and auditory capturing. In the third phase, the co-occurrences remained similar except for attention and action control. It seems that pupils with fine motor difficulties benefited the most from the use of smartphones in activity and inquiry processes.

\subsection{Communicative Learning Practices}

Previous research has indicated that digital technology and similar methods in knowledge and vocabulary building can increase communication and collaboration among peers (Bishop, 2003; Looi et al., 2001). Our content analysis findings revealed only a few mentions of smartphone use in communicative learning practices in the first phase (Table 4), but, in the second and third phases, pupils were required to collaborate and were encouraged to use smartphones to do so. Half of the collaboration was implemented in virtual environments, but there were also mentions of specific group roles and continuing the group work at home. This was further prominent in the co-occurrence network analysis (Figure 3), in which we found a very strong co-occurrence (thick line) between collaboration, virtual environments, and group role in both the second and third phases. It was clarified in the final-interviews that the LD pupils felt that they participated in group work mostly by searching for information using their smartphones. The digital technology provided a special role for LD pupils in a group. For example, pupils mentioned having a specific role in a group, such as searching for information or making either visual or textual notes.

Interviewer (I): So, what do you do in a group? What is your role in it?

Tuomas: Well, I search for information quite often and write it down.

..

I: But, what do you do in a group generally?

Anni: Well, maybe I search for information about something. If there is someone to make a presentation in the group, I usually search photos and like that. And then I wrote some texts too.

Smartphones also incited collaboration among the pupils. In both the second and third phases, the smartphone was used as a communication tool in the virtual environment to explain concepts in collaborative note-making. In the second phase, the dark green collaboration node was the most important, but, in the third phase, the very strong co-occurrences with textual and visual note-making (thick lines) remained. In the second phase, strong co-occurrences with attention and action control, fine motor skills, and language were also found. In the third phase, the capturing learning moment became the most important node. There were also a few mentions of sending messages to group members in the second phase. Pupils also contacted the teacher often. According to the teacher's memos, five pupils contacted the teacher several times, especially in the first phase. Lauri, who presented with difficulties in self-esteem, contacted teacher the most, but it diminished in the second and third phases.

\section{Discussion}

In this study, we presented how LDs could be supported with smartphones in an inclusive primary science class. The pedagogy in the class relied on Florian's (2014) IPAA framework, and smartphone usage was founded on previous studies of the best digital technology practices (see Section 2). The smartphone use was refined over the two-year period, giving pupils and teachers time to get to know the digital tool's potential and to find the most beneficial ways to use it. From the very beginning of the study, pupils and teachers found that the smartphones were beneficial for supporting learning in science lessons. While pupils did not adapt the same supporting practices, they all chose the most beneficial ways for themselves. Furthermore, smartphone usage was beneficial for all LD pupils, especially for pupils with LDs in attention and action control, fine motor skills (cf., Freeman et al., 2004), and language (cf., MacArthur, 2009) but also for pupils with difficulties in self-esteem at the beginning of the study. Working with different scientific learning practices and the smartphone's related technical capabilities influenced how the tool was used. In the first phase, the usage was focused on scientific knowledge and vocabulary building practices, especially in making notes using multimedia tools. This supports findings from previous studies in which multimedia approaches were found to be beneficial for LD pupils in many science learning practices (e.g., Brigham et al., 2011; Tomlinson, 2000). In this study, pupils felt that it was easy to produce visually professional and quality work with smartphones. They learned first how to use smartphones in pedagogically meaningful ways, and this usage developed gradually from individual use to collaborative use. For example, the note-making practices that were learnt assisted LD pupils' studying in the second and third phases' collaborative learning practices.

In order to benefit from digital technologies in inclusive science practices, teachers should be committed to 
fulfilling all of Florian's (2014) inclusive pedagogy assumptions (see also Bešić et al., 2017). In this study, both the teachers and pupils were committed to using the smartphone as a supportive tool. We believe that enhancing pupils' participation in classroom practices increases the development of new, creative ways to use technology in learning. The beliefs of the teachers and pupils that LDs could be circumvented with smartphones was essential. Without this belief, the new digital tool would not have been retained in the science learning practices. In addition, the importance of commitment was explicated in this two-year study, where time was an essential component. At the beginning, LD pupils needed intensified support from teachers in their smartphone use. Sending text-messages and e-mails to the teacher to ensure they completed their tasks diminished gradually. Aligning to what Bouck (2010) and Cook and Schirmer (2003) pinpointed in their studies, it took time in this study to find the best smartphone learning-supportive practices for each pupil.

According to our knowledge, there is a paucity of studies on inclusive science practices and supporting LD pupils with digital technology over an extended period of time. The smartphone usage described in this classroom adds a new example of inclusive pedagogical practice to the research. We believe that our study points out a need for longitudinal research, especially with LD pupils, since it takes time to learn new practices. We also encourage researchers to work as a natural part of the classroom community. Furthermore, the uncommon use of the Gephi co-occurrence network analysis tool enabled us to explore the data visually and to refine the results beyond the more common content analysis method. In our study, the complexity of the inclusive classroom setting, collected data, and the diversity of LD pupils raised the need for a novel analysis tool. We believe that the co-occurrence analysis enriched our data analysis by presenting a visualization of the data, and, therefore, we see its potential in other case studies.

In this study, the benefits of the smartphone in LD-supportive scientific practices depended on time, the device's usability to circumvent LDs in different science learning practices, the teachers' commitment, and close collaboration between the pupils. With available and useful digital technology, there is a need to offer different methods to pupils in order to find the most valuable tools and the best learning practices for each. We agree with McGinnis and Kahn's (2014) literature review findings that LD pupils are able to learn in inclusive science classes without any other significant adaptions than modified practices that allow pupils to circumvent their LD. This applies pressure to publishing companies to provide not only traditionally differentiated learning materials with simplified text but also pedagogically high-quality digital learning material with multimedia resources that can support all learners' knowledge building and digital skills (Song et al., 2012).

We acknowledge that there are limitations in this case study in terms of the uniqueness of the inclusive classroom setting presented and the diversity of the participating pupils. We recognize that conducting the study in a different school with different pupils or using similar inclusive practices to support the learning with other pupils may result in different outcomes due to individual differences and preferences. Also, the inclusive practices used in the class prior study period promoted further science practices development. In addition, not all actions that benefitted pupils' learning were visible in the data; in the final interviews, pupils were asked only about how they used their smartphone and how they felt that it benefited their learning. Therefore, the reader should consider carefully the extent to which the results are transferable to other contexts. Despite these limitations, the findings can be used as an example of supportive smartphone usage for LDs.

\section{Acknowledgments}

This material is based upon work supported by the Academy of Finland, grants 286837 and 294228, and the Strategic Research Council, grant 312527. The opinions expressed herein are those of the authors and do not represent the views of the funding agencies.

\section{References}

Basic Education Act. (628/1998; Perusopetuslaki), section 30 (as amended by Act 642/2010), section 31, and section 31 a(1) (as amended by Act 477/2003).

Bastian, M., Heymann, S., \& Jacomy, M. (2009). Gephi: an open source software for exploring and manipulating networks. International AAAI Conference on Weblogs and Social Media.

Bell, D. (1998). Assessing science: Challenges faced by teachers of children with learning difficulties in primary schools. Support for Learning, 13(1), 26-31. https://doi.org/10.1111/1467-9604.00051

Bell, D. (2002). Making science inclusive: providing effective learning opportunities for children with learning difficulties. Support for Learning, 17(4), 156-161. https://doi.org/10.1111/1467-9604.00258

Bešić, E., Paleczek, L., Krammer, M., \& Gasteiger-Klicpera, B. (2017). Inclusive practices at the teacher and class level: the experts' view. European Journal of Special Needs Education, 32(3), 329-345. 
https://doi.org/10.1080/08856257.2016.1240339

Bishop, J. (2003). The Internet for educating individuals with social impairments. Journal of Computer Assisted Learning, 19(4), 546-556. https://doi.org/10.1046/j.0266-4909.2003.00057.x

Bouck, E. C. (2010). Technology and students with disabilities: Does it solve all the problems? In F. E. Obiakor, J. P. Bakken \& A. F. Rotatori (Eds.), Current issues and trends in special education: Research, technology, and teacher preparation (Advances in special education, pp. 91-104). Bingley, UK: Emerald Group. https://doi.org/10.1108/S0270-4013(2010)0000020009

Brigham, F., Scruggs, T., \& Mastropieri, M. (2011). Science education and students with learning disabilities. Learning Disabilities Research \& Practice, 26(4), 223-232. https://doi.org/10.1111/j.1540-5826.2011.00343.x

Brodin, J., \& Lindstrand, P. (2003). What about ICT in special education? Special educators evaluate information and communication technology as a learning tool. European Journal of Special Needs Education, 18(1), 71-87. https://doi.org/10.1080/0885625032000042320

Cohen, L., Manion, L., \& Morrison, K. (2007). Research Methods in Education (6th ed.). New York: Routledge. https://doi.org/10.4324/9780203029053

Cook, B. G., \& Schirmer, B. R. (2003). What is Special About Special Education: Overview and Analysis. The Journal of Special Education, 37(3), 200-205. https://doi.org/10.1177/00224669030370031001

Drigas, A., \& Ioannidou, R. E. (2013). Special Education and ICTs. International Journal of Emerging Technologies in Learning, 8(2), 41-47. https://doi.org/10.3991/ijet.v8i2.2514

Fasting, R. B., \& Halaas Lyster, S. A. (2005). The effects of computer technology in assisting the development of literacy in young struggling readers and spellers. European Journal of Special Needs Education, 20(1), 2140. https://doi.org/10.1080/0885625042000319061

Finnish National Agency of Education. (2016). The Finnish core curriculum for basic education 2014. The Finnish National Board of Education.

Florian, L. (2010). Special education in an era of inclusion: The end of special education or a new beginning? The Psychology of Education Review, 34(2), 22-30.

Florian, L. (2014). What counts as evidence of inclusive education? European Journal of Special Needs Education, 29(3), 286-294. https://doi.org/10.1080/08856257.2014.933551

Freeman, A. R., MacKinnon, J. R., \& Miller, L. T. (2004). Assistive technology and handwriting problems: What do occupational therapists recommend? The Canadian Journal of Occupational Therapy, 71(3), 150-160. https://doi.org/10.1177/000841740407100305

Geer, R., \& Sweeney, T. A. (2011). Students' voices about learning with technology. Journal of Social Sciences, $8(2), 294-303$.

Gersten, R., \& Edyburn, D. (2007). Defining Quality Indicators for Group Designs in Special Education Technology Research. Journal of Special Education Technology, 22(3), 3-18. https://doi.org/10.1177/016264340702200302

Graham, L. J., \& Jahnukainen, M. (2011). Wherefore art thou, inclusion? Analysing the development of inclusive education in New South Wales, Alberta and Finland. Journal of Education Policy, 26(2), 263-288. https://doi.org/10.1080/02680939.2010.493230

Hu, Y. (2006). Efficient, High-Quality Force-Directed Graph Drawing. The Mathematica Journal, 10(1), 37-71.

Johnson, D. W., \& Johnson, F. P. (2013). Joining Together: Group Theory and Group Skills (11th ed.). New Jersey: Pearson.

Khokhar, D. (2015). Gephi Cookbook (Kindle ed.). Birmingham: Packt Publishing.

Krajick, J., \& Merritt, J. (2012). Engaging students in scientific practices: What does constructing and revising models look like in the science classroom? Understanding a framework for K-12 science education. Science Teacher, 79(3), 38-41.

Lee, O., \& Buxton, C. (2011). Engaging Culturally and Linguistically Diverse Students in Learning Science. Theory into Practice, 50, 277-284. https://doi.org/10.1080/00405841.2011.607379

Lee, O., \& Fradd, S. H. (1996). Literacy Skills in Science Learning among Linguistically Diverse Students. 
Science

Education,

$80(6)$

$651-671$. https://doi.org/10.1002/(SICI)1098-237X(199611)80:6<651::AID-SCE2>3.0.CO;2-I

Lee, T. T. H., \& So, W. W. M. (2014). Inquiry learning in a special education setting: managing the cognitive loads of intellectually disabled students. European Journal of Special Needs Education, 30(2), 156-172. https://doi.org/10.1080/08856257.2014.986907

Looi, C. K., Zhang, B., Chen, W., Seow, P., Chia, G., Norrist, C., \& Soloway, E. (2011). 1:1 mobile inquiry learning experience for primary science students: a study of learning effectiveness. Journal of Computer Assisted Learning, 27, 269-287. https://doi.org/10.1111/j.1365-2729.2010.00390.x

MacArthur, C. A. (2009). Reflections on Research on Writing and Technology for Struggling Writing Writers. Learning Disabilities Research \& Practice, $24(2), \quad 93-103$. https://doi.org/10.1111/j.1540-5826.2009.00283.x

McGinnis, J. R., \& Kahn, S. (2014). Special needs and talents in science learning. In N. Lederman \& S. K. Abell (Eds.), Handbook of research on science education (Vol. II, pp. 223-245). New York, NY: Routledge.

Moeller, J., Ivcevic, Z., Brackett, M. A., \& White, A. E. (2017). Mixed Emotions: Network Analyses of Intra-Individual Co-occurrences Within and Across Situations. Retrieved from https://osf.io/b4cxt/

Motiwalla, L. F. (2007). Mobile learning: A framework and evaluation. Computer \& Education, 49, 581-596. https://doi.org/10.1016/j.compedu.2005.10.011

Niilo Mäki Instituutti. (2015). Clinic for learning difficulties. Retrieved from http://www.nmi.fi/en/lastentutkimusklinikka-en

OECD. (2016). PISA 2015 Assessment and Analytical Framework: Science, Reading, Mathematic and Financial Literacy. Paris: OECD Publishing. https://doi.org/10.1787/9789264255425-en

O'Leary, S. (2011). The Inclusive Classroom: Effect of a readability intervention on student engagement and on-task behaviour within two mixed-ability science classrooms. Science Education International, 22(2), $145-151$.

Paju, B., Räty, L., Pirttimaa, R., \& Kontu, E. (2016). The school staff's perception of their ability to teach special educational needs pupils in inclusive settings in Finland. International Journal of Inclusive Education, 20(8), 801-815. https://doi.org/10.1080/13603116.2015.1074731

Pesonen, H., Itkonen, T., Jahnukainen, M., Kontu, E., Kokko, T., Ojala, T., \& Pirttimaa, R. (2014). The implementation of new special education legislation in Finland. Educational Policy, 29(1), $162-178$. https://doi.org/10.1177/0895904814556754

Paranyushkin, D. (2011). Identifying the Pathways for Meaning Circulation Using Text Network Analysis. Berlin, Germany: Nodus Labs.

Sakarneh, M., \& Nair, N. A. (2014). Effective Teaching in Inclusive Classroom: Literature Review. Journal of Education and Practice, 5(24), 28-34.

Song, Y., Wong, L. H., \& Looi, C. K. (2012). Fostering personalized learning in science inquiry supported by mobile technologies. Special Issue on Personalized Learning, 60, 679-701. https://doi.org/10.1007/s11423-012-9245-6

Sormunen, K., Juuti, K. \& Lavonen, J. (in press). Reflective discussion as a method of supporting participation in maker-centered science project. International Journal of Science and Mathematics Education.

Sormunen, K., Lavonen, J., \& Juuti, K. (2014). Crossing classroom boundaries in science teaching and learning through the use of smartphones. In H. Niemi, J. Multisilta, \& E. Löfström (Eds.), Crossing boundaries for learning-through technology and human efforts (pp. 91-109). Helsinki: University of Helsinki, CICERO Learning Network.

Stake, R. (2005). Qualitative Case Studies. In N. Denzin \& Y. Lincoln (Eds.), The SAGE Handbookf Qualitative Research (3rd ed., pp. 443-466). Thousand Oaks, London, New Delhi: Sage.

Stalker, K. (1998). Some Ethical and Methodogical Issues in Research with people with Learning Difficulties. Disability \& Society, 13(1), 5-19. https://doi.org/10.1080/09687599826885

Tochon, F. V. (2007). From video cases to video pedagogy: A framework for video feedback and reflection in pedagogical research praxis. In R. Goldman, R. Pea, B. Barron \& S. J. Derry (Eds.), Video Research in the Learning Sciences (pp. 53-66). New Jersey: Routledge. 
Tomlinson, C. A. (2000). Differentiation of Instruction in the Elementary Grades. Clearinghouse on Elementary and Early Childhood Education.

Wellington, W., \& Wellington, J. (2002). Children with communication difficulties in mainstream science classrooms. School Science Review, 83(305), 81-92.

\section{Copyrights}

Copyright for this article is retained by the author, with first publication rights granted to the journal.

This is an open-access article distributed under the terms and conditions of the Creative Commons Attribution license (http://creativecommons.org/licenses/by/4.0/). 